\title{
Tuning to the right signal
}

\author{
Mark O. Huising ${ }^{1,2}$
}

Received: 25 February 2015 / Accepted: 10 March 2015 / Published online: 26 March 2015

(C) Springer-Verlag Berlin Heidelberg 2015

\begin{abstract}
Pancreatic beta cells are clustered in islets of Langerhans together with alpha cells in an arrangement that facilitates the tight coordination of insulin and glucagon secretion at the source of their release. Other secretory cells, including somatostatin-secreting delta cells and pancreatic polypeptide cells, co-localise with alpha and beta cells in the islet and serve to modulate islet endocrine output. A multitude of non-secretory cell types, including endothelial cells, pericytes, stromal cells, glial cells and macrophages, complete the cellular make up of the islet, which is further enhanced by (para)sympathetic nerve terminals that impinge on the islets via neurotransmitters released in the islet microenvironment. While this islet architecture is relatively simple compared with the vast complexity of the central nervous system, the constellation of cell types united in the islet nevertheless provides a rich substrate for local paracrine and autocrine interactions that affect diverse aspects of islet physiology, ranging from the modulation of hormone secretion to the regulation of islet cell mass via proliferation and death. In this issue of Diabetologia (DOI: 10.1007/s00125-015-3552-5), Yang et al take the notion of rich crosstalk within the islet as their point of departure for a systematic evaluation of the beta cellprotective properties of an extensive panel of over 200 factors,
\end{abstract}

Mark O. Huising

mhuising@ucdavis.edu

1 Department of Neurobiology, Physiology and Behavior, College of Biological Sciences, University of California, One Shields Avenue, Davis, CA 95616, USA

2 Department of Physiology and Membrane Biology, School of Medicine, University of California, Davis, CA, USA with some surprising and highly interesting results, as discussed in this commentary.

Keywords Beta cell ER stress · Beta cell survival · Glucotoxicity · High-content screen · Islet · Lipotoxicity · Paracrine interactions

$\begin{array}{ll}\text { Abbreviations } \\ \text { GFP } & \text { Green fluorescent protein } \\ \text { GH } & \text { Growth hormone } \\ \text { IL1R1 } & \text { IL-1 receptor, type 1 } \\ \text { OLFM1 } & \text { Olfactomedin 1 } \\ \text { PI } & \text { Propidium iodide } \\ \text { SEMA4a } & \text { Semaphorin4a }\end{array}$

Maintenance of beta cell mass is determined by the net effect of beta cell proliferation and beta cell death. Beta cell proliferation is abundant in juvenile rodent islets, declines rapidly with age, but can be stimulated by a variety of factors, including incretins, prolactin and insulin growth factors [1]. However, stimulation of human beta cell proliferation has proven much more elusive [2], which provides all the more incentive to prevent loss of beta cells from death in response to diabetesassociated insults that are major contributors to disease [3]. In this issue of Diabetologia, Carol Yang, Quin Wills and Jim Johnson systematically evaluate the beta cell-protective properties of an extensive panel of over 200 factors on primary mouse beta cells [4]. These factors were selected on the basis of the expression of their cognate receptors in mouse or human islets, derived from prior work by the authors [5] among many others [6-10]. Recognising that beta cell stress in diabetes can occur in many different shapes and forms [3], each 
factor was systematically evaluated in five distinct islet cell culture conditions, reflective of different type 1 or type 2 diabetes-associated stresses. To prevent confounding actions of survival factors in fetal bovine serum, each beta cell stress condition was designed as an extension of serum starvation under $5.5 \mathrm{mmol} / \mathrm{l}$ glucose. Tested paradigms included $20 \mathrm{mmol} / \mathrm{l}$ glucose (glucotoxicity), palmitate (lipotoxicity), thapsigargin (endoplasmic reticulum stress) and treatment with a cocktail of IL- $1 \beta$, TNF $\alpha$ and IFN $\gamma$ (which reflect proinflammatory insults associated with both type 1 and type 2 diabetes). To enable the recognition of beta cells, the entire study was conducted on freshly isolated primary wild type mouse islets. Select validation experiments were carried out on islets from the mouse insulin promoter (MIP)-driven GFP transgenic reporter mouse [11], which was one of several lines recently reported to contain a human growth hormone $(\mathrm{GH})$ minigene that drives local production of $\mathrm{GH}$ and serotonin [12]. Cell cultures were stained with Hoechst and propidium iodide (PI), with the loss of Hoechst positivity and the accumulation of PI among GFP-positive beta cells quantified every $3 \mathrm{~h}$ as indices of beta cell death. The result is an impressive screen that features live-cell, high-content imaging data of primary beta cells that is unique in scope and ambition. Such a comprehensive overview of factors precludes the depth we would normally expect from papers that focus on individual factors, but this was not the purpose of this study. Instead, the value and novelty of this work is in its breadth, complemented by the fact that so many factors are benchmarked directly against each other for their ability to protect primary beta cells against death induced by several treatments.

This systematic screen of primary islet cells represents a significant improvement on the majority of previous screening efforts that have been carried out on cell lines. The authors opted to carry out their study on mouse islets (and not human islets) for entirely justifiable reasons, as it is difficult to control for the variation between human islet donors when conducting screens of this magnitude that are conducted over the course of several years. However, the use of rodent models as a proxy for human disease comes at the risk of identifying signals that protect mouse but not human beta cells against death. For example, systematic comparison of the transcriptomes of purified mouse and human beta cells revealed that human beta cells, in contrast to mouse beta cells, express very few to no receptors for the related cytokines prolactin, GH or ciliary neurotrophic factor $[13,14]$. This would suggest that potential protective effects of these factors may not translate to human beta cells. Similarly, mouse beta cells express very high levels of the type 1 IL-1 receptor message and protein (Il1r1/IL1R1) [13], while the expression of IL1R1 in human islets is markedly lower and enriched in non-beta cells [14], which raises the question of whether human beta cells would show an equally robust response to an insult mediated by a cytokine cocktail that included IL- $1 \beta$. Of course, in most studies on mouse beta cells $[4,13]$ they are isolated from adults whose age is measured in months; a confounder that is difficult to avoid when using mouse beta cells to model diseases of the adult human islet.

Perhaps the most surprising outcome of this study is that relatively few factors emerged with pan-protective effects across each of the distinct beta cell insults tested [4]. Among these were adiponectin and vasoactive intestinal peptide, which are known to stimulate beta cells, and somatostatin. The latter thus promotes beta cell survival despite inhibiting insulin release. Of course, somatostatin is a potent inhibitor of glucagon release [15], which opens up the possibility that some of the actions of somatostatin, and possibly other factors in this screen, are mediated through intermediates derived from non-beta cells in co-culture. Notably absent from the list of pan-protective factors were the incretins, gastric inhibitory polypeptide and glucagon-like peptide 1, and oxyntomodulin, which is derived from the same pre-pro-glucagon precursor and promotes glucose-stimulated insulin release [16]. This in spite of the fact that incretins are often regarded as beneficial for their ability to promote rodent beta cell proliferation and survival [17]. Perhaps the known peptide instability of the natural pre-pro-glucagon-derived peptides contributed to their inconsistent performance as pan-beta cell protectors across all conditions tested; there is significant dipeptidyl peptidase 4 gene (Dpp4) expression in mouse beta cells [13, 18]. More stable incretin analogues, such as exendin4 were not included in the screen, as it focused on endogenous factors. One of the lesser known factors that emerged to convey good overall protection against all beta cell insults tested in the screen on primary mouse beta cells is olfactomedin 1 (OLFM1). OLFM1 is a member of a larger family of glycoproteins that was initially purified from olfactory neuroepithelium. OLFM1 is implicated in early neurodevelopment and axon growth [19], but had no known function in islets. In following up on the identification of OLFM1 as a beta cell protective factor in a screen on mouse beta cells, the authors show that its beta cell-protective properties translate to human beta cell protection under similar conditions in vitro [4].

In addition to the identification of factors that prevent beta cell death across a broad spectrum of insults, Yang et al find that each of the different beta cell stress paradigms is associated with a relatively distinct sets of protective factors [4]. This suggests that beta cells are protected from different types of insults through mechanistically distinct pathways. A case in point is semaphorin $4 \mathrm{a}$ (SEMA4a), which was found to have strong protective effects against beta cell lipotoxic insults, but actually promoted beta cell death under other conditions [4]. Members of the semaphorin family were originally discovered as repulsive axon guidance cues, but SEMA4a also plays important roles in the immune system, where it is expressed on the membrane of dendritic cells and interacts with T cell surface receptors to provide co-stimulation in T helper type 1 cell 
differentiation [20]. However, as is the case for OLFM1, SEMA4a had not previously been associated with beta cell function, which illustrates the power of non-biased efforts such that by Yang et al to identify entirely novel factors that contribute to beta cell survival. More generally speaking, prevention of palmitate-induced beta cell death was more strongly associated with tyrosine kinase receptors, while protection against proinflammatory cytokines was more strongly associated with $\mathrm{G} \alpha \mathrm{q}$-mediated $\mathrm{G}$ protein-coupled receptors. The finding that relatively distinct signalling pathways are associated with protection against different types of beta cell insults is unexpected. It also suggests significant synergistic potential by co-stimulation with factors that are selectively protective against glucotoxicity and lipotoxicity to maximise beta cell protection in type 2 diabetes. These results by Yang et al will hopefully serve as a catalyst to the field of islet biology by providing a wealth of novel information regarding the beta cell-protective effect of several hundred signals endogenous to the islet. As diabetes is a disease that manifests itself in many shapes and forms, an increased understanding of the specific pathways that ensure maximal protection in the face of death precipitated by distinct beta cell insults would be a significant step towards the development of personalised medicine for the treatment of diabetes.

Funding MOH is supported by a JDRF Career Development Award No. 2-2013-54.

Duality of interest The author declares that there is no duality of interest associated with this manuscript.

Contribution statement The author was the sole contributor to this paper.

\section{References}

1. Mezza T, Kulkarni RN (2014) The regulation of pre- and postmaturational plasticity of mammalian islet cell mass. Diabetologia 57:1291-1303

2. Kulkarni RN, Mizrachi EB, Ocana AG, Stewart AF (2012) Human beta-cell proliferation and intracellular signaling: driving in the dark without a road map. Diabetes 61:2205-2213

3. Quan W, Jo EK, Lee MS (2013) Role of pancreatic beta-cell death and inflammation in diabetes. Diabetes Obes Metab 15(Suppl 3): 141-151
4. Yang YHC, Wills QF, Johnson JD (2015) A live-cell, high-content imaging survey of 206 biologic factors across 5 stress conditions reveals context-dependent survival effects in primary beta-cells. Diabetologia. doi:10.1007/s00125-015-3552-5

5. Yang YHC, Szabat M, Bragagnini C et al (2011) Paracrine signalling loops in adult human and mouse pancreatic islets: netrins modulate beta cell apoptosis signalling via dependence receptors. Diabetologia 54:828-842

6. Rodriguez-Diaz R, Dando R, Jacques-Silva MC et al (2011) Alpha cells secrete acetylcholine as a non-neuronal paracrine signal priming beta cell function in humans. Nat Med 17:888-892

7. Kutlu B, Burdick D, Baxter D et al (2009) Detailed transcriptome atlas of the pancreatic beta cell. BMC Med Genet 2:3

8. Rodriguez-Diaz R, Abdulreda MH, Formoso AL et al (2011) Innervation patterns of autonomic axons in the human endocrine pancreas. Cell Metab 14:45-54

9. Brissova M, Aamodt K, Brahmachary P et al (2014) Islet microenvironment, modulated by vascular endothelial growth factor-A signaling, promotes beta cell regeneration. Cell Metab 19:498-511

10. Caicedo A (2013) Paracrine and autocrine interactions in the human islet: more than meets the eye. Semin Cell Dev Biol 24:11-21

11. Hara M, Wang X, Kawamura T et al (2003) Transgenic mice with green fluorescent protein-labeled pancreatic beta-cells. Am J Physiol Endocrinol Metab 284:E177-E183

12. Brouwers B, de Faudeur G, Osipovich AB et al (2014) Impaired islet function in commonly used transgenic mouse lines due to human growth hormone minigene expression. Cell Metab 20: 979-990

13. Benner C, van der Meulen T, Caceres E, Tigyi K, Donaldson CJ, Huising MO (2014) The transcriptional landscape of mouse beta cells compared to human beta cells reveals notable species differences in long non-coding RNA and protein-coding gene expression. BMC Genomics 15:620

14. Nica AC, Ongen H, Irminger JC et al (2013) Cell-type, allelic, and genetic signatures in the human pancreatic beta cell transcriptome. Genome Res 23:1554-1562

15. Schuit FC, Derde MP, Pipeleers DG (1989) Sensitivity of rat pancreatic A and B cells to somatostatin. Diabetologia 32:207-212

16. Prothiwa M, Syed I, Huising MO et al (2014) Data-driven synthesis of proteolysis-resistant peptide hormones. J Am Chem Soc 136: $17710-17713$

17. Drucker DJ (2013) Incretin action in the pancreas: potential promise, possible perils, and pathological pitfalls. Diabetes 62:33163323

18. Omar BA, Liehua L, Yamada Y, Seino Y, Marchetti P, Ahrén B (2014) Dipeptidyl peptidase 4 (DPP-4) is expressed in mouse and human islets and its activity is decreased in human islets from individuals with type 2 diabetes. Diabetologia 57:1876-1883

19. Anholt RR (2014) Olfactomedin proteins: central players in development and disease. Front Cell Dev Biol 2:6

20. Takamatsu H, Okuno T, Kumanogoh A (2010) Regulation of immune cell responses by semaphorins and their receptors. Cell Mol Immunol 7:83-88 